\title{
Silêncios no pampa: breves pontuações sobre a imagem do gaúcho na pintura rioplatense e brasileira
}

\author{
Silences in the pampa: brief observation about the image of the
} gaucho in the rioplatense and brazilian painting

\author{
Enviado em: $17 / 05 / 2018$ \\ Aceito em: 29/07/2018 \\ Luciana da Costa de Oliveira ${ }^{1}$
}

\section{Resumo:}

Colocar-se frente a uma imagem é permitir-se, também, defrontar-se com silêncios. Tais fontes, que são suportes que evocam presença, igualmente guardam para si inúmeros vazios. Se pensarmos que ela nasce da morte e da necessidade de tornar visível o que se transformou em invisível, estaremos diante de um paradoxo: como algo que chama o ausente pode comportar silêncios? É pensando nessa problemática específica relacionada ao uso da imagem, que se pretende debater suas particularidades. Nesse sentido, observando os diversos fios que tramaram a complexa rede de construção da imagem do gaúcho na pintura platina e brasileira, é que se objetiva problematizar os silêncios no pampa. Para que seja possível a análise, será empreendido um estudo acerca da obra dos artistas Aldo Locatelli, Cesáreo Bernaldo de Quirós, Pedro Figari e Pedro Weigärtner.

Palavras-chave: Gaúcho. Pintura platina. Pintura brasileira.

\begin{abstract}
:
Standing in front of an image is to allow himself/herself to face silences. These imaging sources are material effigies that evoke presence and hold to themselves innumerable voids. If we think that an image is possibly born from death and from the need to make visible what has become invisible, we will face a paradox: how can something that relates to the absent be silent? Thinking about this specific problem concerning the use of the image, we intend to discuss its particularities. Thus, observing the many threads that have shaped the construction of a complex image of the Gaucho in Brazilian and Platine painting, we aim at questioning the silences in the Pampa region. In order to
\end{abstract}

${ }^{1}$ Doutora em História das Sociedades Ibéricas e Americanas pela Pontifícia Universidade Católica do Rio Grande do Sul. 
accomplish this objective, we will survey the master works of Aldo Locatelli, Cesáreo Bernaldo de Quirós, Pedro Figari and Pedro Weigärtner.

Keywords: Gaucho. Platine painting. Brazilian painting.

Jayme Caetano Braun, poeta que trilhou e declamou o pampa em palavras, certa feita escreveu: "o silêncio é a luz mais pura no mundo onde me deparo; e a luz é o silêncio claro na estrada de quem procura". Para o payador, o silêncio é luz que direciona, que clareia e que faz achar o que se subtrai e se esconde do olhar. O silêncio evocado por Caetano Braun poderia, igualmente, evidenciar a forma com a qual os silêncios perpassam a pesquisa histórica, atuam junto às fontes de pesquisa e produzem novos conhecimentos. São elementos de grande valia para o pesquisador pois, uma vez que desacomodam, perturbam e intrigam, igualmente promovem o aparecimento de novos problemas.

O estudo e análise de imagens, por certo, não é um campo novo de pesquisa. No entanto, as novas abordagens acerca dessas fontes, especialmente as que estão voltadas às suas especificidades, oportunizam trabalhar e tecer novos conhecimentos. $A$ partir do momento em que se empreendem estudos interdisciplinares e, ainda,se observa o documento imagético a partir de sua natureza antropológica, é possibilitado um maior afastamento das interpretações que ponderavam, apenas, o seu aspecto formal e os percebiam como ilustrações ou conclusões de textos escritos.

Nesse sentido, partindo de tais questões, o presente texto visa debater a forma com a qual os silêncios atuam - e perturbam -a pesquisa que tem por base as fontes visuais. Para tanto, as produções imagéticas acerca do pampa e do gaúcho platino e brasileiro servirão de base para as problematizações que aqui se pretende levantar. Será, então, a partir da obra de quatro artistas que detiveram sua produção na imagem do homem do campo, que quatro problemas teórico-metodológicos serão abordados.

Como forma de iniciar o debate acerca dos silenciamentos no trabalho com imagens, é interessante estabelecer como ponto de partida um dos questionamentos incitadores de uma pesquisa que teve como objetivo maior analisar a maneira com a qual 
a imagem do gaucho e do gaúcho foram construídas na pintura argentina, uruguaia e brasileira. ${ }^{2}$ É precisamente a partir dele que as questões que aqui se pretende esboçar estarão encadeadas. Assim, propor um trabalho que tenha como tema central a construção da imagem do gaúcho no Brasil e países platinos é, pois, imergir em um mundo de múltiplas possibilidades. E essa multiplicidade - e complexidade - temática apresentou-se pela primeira vez no transcurso das pesquisas para a dissertação de Mestrado que, dentre outras questões, objetivava analisar a produção muralística nãoreligiosa de Aldo Locatelli (1915-1962), especialmente a que está localizada nas três grandes salas do Palácio Piratini, em Porto Alegre.

Investigar os murais que o artista ítalo-brasileiro havia executado no interior do palácio do governo entre os anos de 1951 e 1955, onde o tema estava centrado em aspectos específicos do Rio Grande do Sul, problematizava não só a história sulriograndense e o desenvolvimento do Estado até o momento da execução das pinturas. Ela trazia, também, a figura do gaúcho junto aos elementos que o conectavam tanto à história sulina quanto ao papel por ele desempenhado no século XX.

Mesmo após o término da dissertação, muitas questões ainda permaneciam latentes, especialmente as que, mais uma vez, voltavam-se para o gaúcho e para a elaboração de sua imagem. Indagações que versavam sobre a forma e o momento em que esse tipo social da campanha se fez presente na pintura brasileira e, sobretudo, na riograndense, ganharam novas dimensões e ampliaram o leque de possibilidades de análise. Ao dar os primeiros passos em direção a tal objeto, onde obras como a dos irmãos Moreaux e a de Angelo Agostini, no Rio de Janeiro, e a de Pedro Weingärtner, no Rio Grande do Sul, desdobravam-se como as primeiras pistas de um labirinto silencioso, uma busca peculiar acabou por ampliar o questionamento inicial e conduziu a pesquisa para uma área muito mais ampla de estudo.

Ao levar a cabo uma investigação em sites da internet acerca da produção imagética do gaúcho, objetivando encontrar artigos, referências e demais produções pictóricas acerca do tema, uma postagem - e uma imagem - tornaram-se recorrentes nas buscas realizadas. Estas, que diziam respeito à Guerra dos Farrapos (1835-1845), focava

\footnotetext{
${ }^{2} \mathrm{~A}$ citada pesquisa foi a base da tese intitulada "Da imagem nascente à imagem consagrada: a construção da imagem do gaúcho pelos pincéis de Cesáreo Bernaldo de Quirós, Pedro Figari e Pedro Weingärtner", defendida no ano de 2017 no Programa de Pós-Graduação em História da PUCRS. Para maiores detalhamentos, ver: OLIVEIRA, Luciana da Costa de. Da imagem nascente à imagem consagrada: a construção da imagem do gaúcho pelos pincéis de Cesáreo Bernaldo de Quirós, Pedro Figari e Pedro Weingärtner. Porto Alegre, 2017. Tese (Doutorado em História) - Escola de Humanidades, Pontifícia Universidade Católica do Rio Grande do Sul.
} 
sua atenção na participação dos Lanceiros Negros no conflito. Tais publicações, que apresentavam textos bem escritos e com muitas referências, eram bastante interessantes e fundamentados a não ser por uma questão: o uso de uma imagem. Esta, de autoria do pintor uruguaio Juan Manuel Blanes (1830-1901), e intitulada Lancero da época de Rivera ([s.d.]), ilustrava a atividade dos Lanceiros Negros na Revolução Farroupilha. Ou seja, por uma necessidade visual, um lancero uruguaio acabou por ser utilizado para contemplar visualmente a atividade dos lanceiros farroupilhas.

Perceber tal questão, que em seu interior trazia inúmeros equívocos, mas também incontáveis possibilidades, direcionou a pesquisa para dois sentidos: o primeiro, relacionado à forma com a qual a imagem do gaúcho foi - e ainda é - largamente utilizada - e, algumas vezes, de forma equivocada - em diversas produções escritas quando são tomadas apenas como ilustração de textos. E o segundo, e que ampliou a pergunta inicial do projeto, foi pensar e problematizar a sua imagem não apenas no Brasil, mas igualmente em países como Argentina e Uruguai, onde ele também é elemento de grande importância histórica e cultural.

Para o texto que ora se apresenta, mesmo que os problemas levantados estejam mais centrados em questões voltadas aos métodos de trabalho e análise imagética, a produção pictórica dos artistas argentinos, uruguaios e brasileiros serão de fundamental importância para evidenciar a forma como os silêncios perpassam as imagens. Destarte, inicia-se a presente reflexão fazendo-se um questionamento bastante amplo: o que parece silenciado quando, na análise de imagens, suas diversificadas especificidades não são consideradas? A resposta à indagação, que irá se desdobrar em quatro pontos centrais, será construída a partir da tessitura de relações entre a obra do argentino Cesáreo Bernaldo de Quirós (1879-1968), do uruguaio Pedro Figari (1861-1938), do brasileiro Pedro Weingärtner (1853-1929) e do ítalo-brasileiro Aldo Locatelli (1915-1962).

Ter a imagem como objeto de estudo é apreender os elementos que estiveram no entorno de sua produção e perceber as inúmeras possibilidades que elas oferecem ao pesquisador. É, também, compreendê-las além das análises que se prendem apenas aos seus aspectos formais ou, ainda, àqueles que vinculam a obra e o artista única e exclusivamente ao seu contexto. Por certo, tais elementos são de fundamental importância. No entanto, se apenas eles são considerados no estudo, acabam por menosprezar as potencialidades oferecidas pelas imagens.

Pensar a obra do artista a partir dos inúmeros fios que a compõem,tal qual uma grande e complexa teia de relações onde estes se interpenetram e produzem novos 
entendimentos, estabelece um estreito vínculo com metodologias que, desde Aby Warburg (1866-1929), percebem e analisam a imagem através do viés antropológico. Para o intelectual, muitos aspectos tornam-se essenciais para a análise imagética. Considerar as relações existentes entre o artista e seu contexto, entre ele e os modelos literários de seu tempo e, ainda, atentar à importância dos comitentes das obras é, também, percorrer um caminho labiríntico que apresenta novos saberes. Para Gertrud Bing, historiadora da arte que, durante muitos anos, conviveu com Aby Warburg em sua biblioteca, a metodologia warburguiana superou

(...) o isolamento que a obra de arte estava ameaçada a sofrer pela contemplação estético-formal e a investigar a complementação recíproca de documentos pictóricos e literários, a relação entre artistas e comitente, o entrelaçamento entre a obra de arte e o ambiente social e sua finalidade prática como objeto individual. (BING, 2013, p. 41).

Assim, da mesma forma que o intelectual alemão, compreende-se aqui a imagem, bem como sua produção, como um fenômeno antropológico. Pelo fato dos elementos culturais serem, igualmente, cristalizados pelas imagens, não são apenas os seus aspectos formais que se conjugam em sua análise, mas sim, e fundamentalmente, os que estão atrelados à memória individual e coletiva. Para o intelectual,

Tanto a memória da personalidade coletiva como a do indivíduo vêm socorrer de um modo todo peculiar o homem artístico, que oscila entre a visão de mundo matemática e a religiosa: ela não o faz criando prontamente o espaço de reflexão, e sim atuando junto aos polos limítrofes do comportamento psíquico, de modo a reforçar a tendência à contemplação serena ou à entrega orgiástica. (2015, p. 363).

Durante esse longo percurso, onde as imagens foram muitas vezes observadas pelas lentes do formalismo e da linearidade temporal, os pensamentos e memórias das quais elas são portadoras foram negligenciados e, por conseguinte, não questionados. Se, como diz Etiènne Samain, "toda a imagem é uma memória de memórias, um grande jardim de arquivos declaradamente vivos" (2012, p. 23), por certo o gaúcho elaborado pelas cores e traços de diferentes artistas sedimentam, em si, essa multiplicidade de pensamentos. Conforme coloca Didi-Huberman,

(...) não ficamos diante da imagem como diante de algo cujas fronteiras exatas não podemos traçar. O conjunto das coordenadas positivas - autor, data, técnica, iconografia, etc. - não basta, evidentemente. Uma imagem, toda imagem, resulta dos movimentos provisoriamente sedimentados ou cristalizados nela (DIDI-HUBERMAN, 2013, p. 33). 
Precisamente esse arcabouço memorialístico que as imagens possuem e que as tornam, nas palavras de Samain, "arquivos vivos", é que vão engendrar um estudo anacrônico voltado, essencialmente, às sobrevivências, ao pós-vida das produções imagéticas. Conceito estruturante dos estudos e pesquisas de Aby Warburg, este está relacionado às imagens que, em determinados momentos, se calam e, em outros, ressurgem. Reaparecem ressignificadas. Perturbam e inquietam quem as observa. São, para o intelectual alemão, sintomas anunciados pelas imagens e pelo tempo fantasmal:

\footnotetext{
Warburg substituiu o modelo ideal das "renascenças", das "boas imitações", e das "serenas belezas" antigas por um modelo fantasmal da história, no qual os tempos já não se calcavam na transmissão acadêmica dos saberes, mas se exprimiam por obsessões, "sobrevivências", remanências, reaparições das formas. Ou seja, por não-saberes, por irreflexões, por inconscientes do tempo (DIDI-HUBRMAN, 2013, p. 25).
}

As imagens perpassam o tempo, desorientam e atravessam a história. São, em última instância, anacrônicas. Constituem-se, nas palavras de Didi-Huberman, por uma montagem de tempos heterogêneos (DIDI-HUBERMAN, 2008, p. 39).

A importância do trabalho de Warburg bem como a de intelectuais que estão baseados em seus preceitos, está, também, na quebra do silêncio que tais objetos, por muitas vezes, apresentaram aos estudiosos. A partir do momento em que uma rede de significações é formada, novas percepções acerca do objeto são construídas da mesma forma em que novos conhecimentos são tecidos.

III

Uma questão que parece permear a produção imagética alusiva ao gaúcho é sua característica auto explicativa. Nesse sentido, mesmo que tais imagens tenham ampla circulação, tanto suas significações quanto o engendramento de suas elaborações, permanecem à margem das análises, isto é, silenciosas e mudas. A partir do momento em que a figuração se sobrepõe às diversas camadas de tempo e memória de que as imagens são depositárias, o estabelecimento de relações e diálogos entre - e por - elas, fica subjugado. Por tal razão, seus usos - e desusos - contribuem, muitas vezes, para um maior distanciamento de novos conhecimentos. Nesse sentido, partindo da obra dos quatro artistas anteriormente mencionados, pretende-se colocar, a partir de quatro problemas de método, a forma com a qual os silêncios perpassam as imagens. 
O primeiro ponto a ser analisado diz respeito à maneira com que a observação dos entornos de produção de uma pintura, especialmente os alusivos à elaboração e construção dos temas, rompem os silenciamentos estabelecidos pelo estudo do que apenas está visível na tela. Junto disso, a percepção das diversas camadas temporais e memorialísticas que estão presentes na pintura, orientam o entendimento da obra para além das formas apresentadas.

Consoante a essa problemática, se pode observar o conjunto de vinte e oito pinturas elaboradas pelo artista argentino Cesáreo Bernaldo de Quirós, intitulada Los Gauchos. Essa série de obras, finalizada no ano de 1927, foi exposta não apenas na América, mas igualmente na Europa, onde foi consagrada pela crítica internacional. Os temas trabalhados por Quirós em Los Gauchos estavam relacionados à paisagem e aos tipos do pampa. Além disso, trazia elementos da história de Entre Rios, sua província natal, através dos inúmeros gauchos federales executados, sobretudo, a partir da cor vermelha.

A maneira com que o artista pensa a produção dessa série está diretamente relacionada aos elementos constitutivos de suas pinturas. Seus gauchos, muito além de evidenciar o homem do pampa, trazia em si um grande arcabouço de memórias particulares. Assim, após muitos anos residindo na Europa, e pensando novos temas para suas pinturas, Bernaldo de Quirós decide retornar ao seu terruño. Isolando-se na residência de Justo José SaénzValienteUrquiza, neto de General Justo José de Urquiza (ZALDIVAR, 1992, p. 174), o artista empreende uma viagem ao interior de Entre Rios onde objetiva vivenciar os modos de vida da gente do interior. Queria conhecer de perto estórias de tempos idos, tradições e costumes peculiares, homens e mulheres que por aqueles campos haviam passado, trazer à tona rostos e cenas que participaram de guerras tão caras à sua província (FOGLIA, 1962, p. 25). Essa viagem ao interior entrerriano proporcionou ao artista uma admirável coleção de memórias e histórias que, conjugadas às suas, contribuíram enormemente para a elaboração de Los Gauchos.

Dentre o vasto conjunto realizado pelo artista, o exemplo que pode aqui ser destacado é a tela intitulada Los degoladores. De toda a série, esta é a única que apresenta uma cena violenta, onde soldados mostram, no primeiro plano, a cabeça cortada de seu oponente, enquanto no segundo, outro soldado prepara-se para degolar outro. As relações que essa pintura estabelece não só com as demais, mas, igualmente, com as memórias e formação do artista, evidenciam questões de grande importância e que, muitas vezes, passam caladas e despercebidas. 
Ao observar a obra, a proximidade com os traços de Goya é evidente, especialmente no que se refere ao uso da luz e à dramaticidade da cena. Isso se baseia, por certo, nos estudos formativos de Quirós que, ao realizá-los na Europa, demonstrou grande interesse pela pintura do artista espanhol. Além dessa questão, sobressai, igualmente, o tema. Como dito anteriormente, o pintor argentino fez de sua série um compêndio acerca do gaucho, onde história, folclore e histórias pessoais se interrelacionavam e dialogavam constantemente.

Figura 01 - Los Degoladores

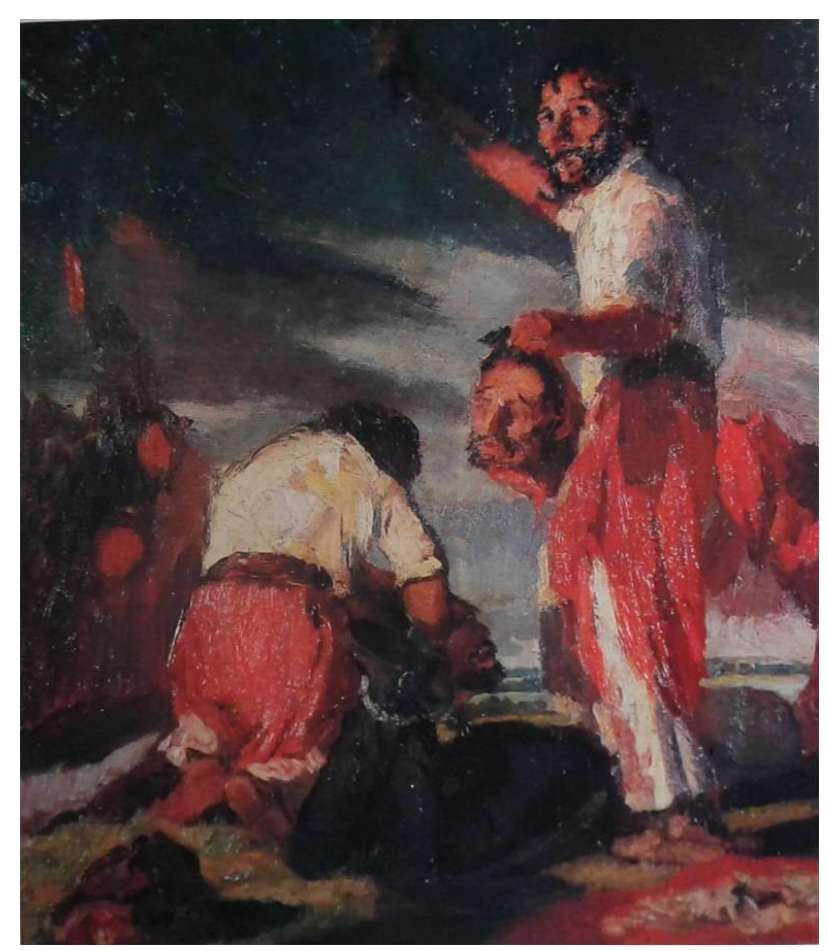

Cesáreo Bernaldo de Quirós

Óleo sobre tela, 1926, 247X227 cm

Museo Nacional de Bellas Artes - Buenos Aires

O caso de Los degoladores é o de uma dessas histórias pessoais. Surgida de um encontro entre o artista e um homem chamado Miranda, este acabou por narrar-lhe que, quando a serviço de um coronel, nas cercanias de Entre Ríos, subjugou muitos de seus desafetos e inimigos, degolando-os (FOGLIA, 1962, p. 26).

Mesmo que brevemente explicitado, o que se percebe quando o olhar e as indagações são direcionados em outro sentido, novos elementos emergem de fontes, por vezes, fartamente estudadas. Buscar na particularidade do artista, através de diários, 
biografias e, também, materiais da imprensa, amplia não só o conhecimento acerca dos entornos da imagem como, também, explora suas potencialidades.

A segunda questão - ou problema - que se objetiva aqui debater, está relacionada não apenas com a formação artística dos pintores, mas igualmente com sua trajetória e trânsito pelos centros intelectuais de sua época. Para tanto, perceber o caminho trilhado pelo uruguaio Pedro Figari (1861-1938) bem como sua obra voltada à cultura popular e, mais especificamente, ao tema do gaucho, reveste-se de singular relevância.

Ao contrário dos demais artistas aqui contemplados, Figari dedicou-se à pintura tardiamente, quando contava, então, com sessenta anos de idade. Mesmo que sua formação não tenha se dado em grandes centros artísticos, pois antes de voltar-se ao mundo das tintas ele havia se dedicado à advocacia e aos cargos políticos, as questões que o levaram a pintar e, além disso, tomar o gaucho como um dos elementos centrais de sua obra, o tornaram um pintor de grande relevância no século XX.

Diferente de Juan Manuel Blanes, por exemplo, que com sua pincelada mais tradicional, elaborou umas das primeiras séries de gauchos uruguaios no século XIX, Figari, dono de uma técnica própria, voltou-se - e problematizou - os temas culturais do Uruguai tendo por base a temática do americanismo e da própria identidade uruguaia. Essa questão pode ser melhor percebida quando se relaciona a obra do artista junto aos contatos estabelecidos com a intelectualidade platina do período, especialmente com Jorge Luis Borges, Ricardo e Manuel Güiraldes.

Mesmo que o próprio Figari tenha sido um importante divulgador de ideias na época, o que se percebe facilmente na imprensa do período, onde muitos de seus textos foram publicados e veiculados, o fato é que seus gauchos estão longe de ser percebidos como portentosos estancieiros ou bravos guerreiros. Eles, pelo contrário, e no entendimento de Figari,são a base formativa da nação, o elemento primitivo e autóctone que, frente às levas migratórias, permanecia como o elo entre passado e presente. Segundo o próprio artista,

(...) olhamos o gaucho como a essência das nossas tradições criollas, como a parte autóctone oposta à conquista ideológica que veio depois da era das emancipações políticas. As cidades ficaram híbridas, há parises, madris, romas, vienas e até berlins nessas terras, enquanto a cidade tradicional ou semitradicional das Américas, elaborada em meio ao cosmopolitismo avassalador (...). (...) ela está na representação superior do gaucho, esse elemento que foi cantado em forma de poesia nas nossas idealizações habituais e que nesse sentido é mais do que um símbolo pátrio: é o símbolo da América Latina(FIGARI, 1924, [s.p.]. 
Tal forma de perceber o gaucho, portanto, conduz o pesquisador a observar mais acuradamente os elementos particulares do artista presentes em suas obras. Figari, da mesma forma que Quirós, se utiliza de suas memórias, emoções e lembranças como peças essenciais para a construção de seus temas, especialmente os gauchescos. Nesse sentido, as manipulações temporais que opera em suas pinturas, bem como a relação com o passado, se tornam questões de suma importância para se acercar de suas pinturas e de seus gauchos.

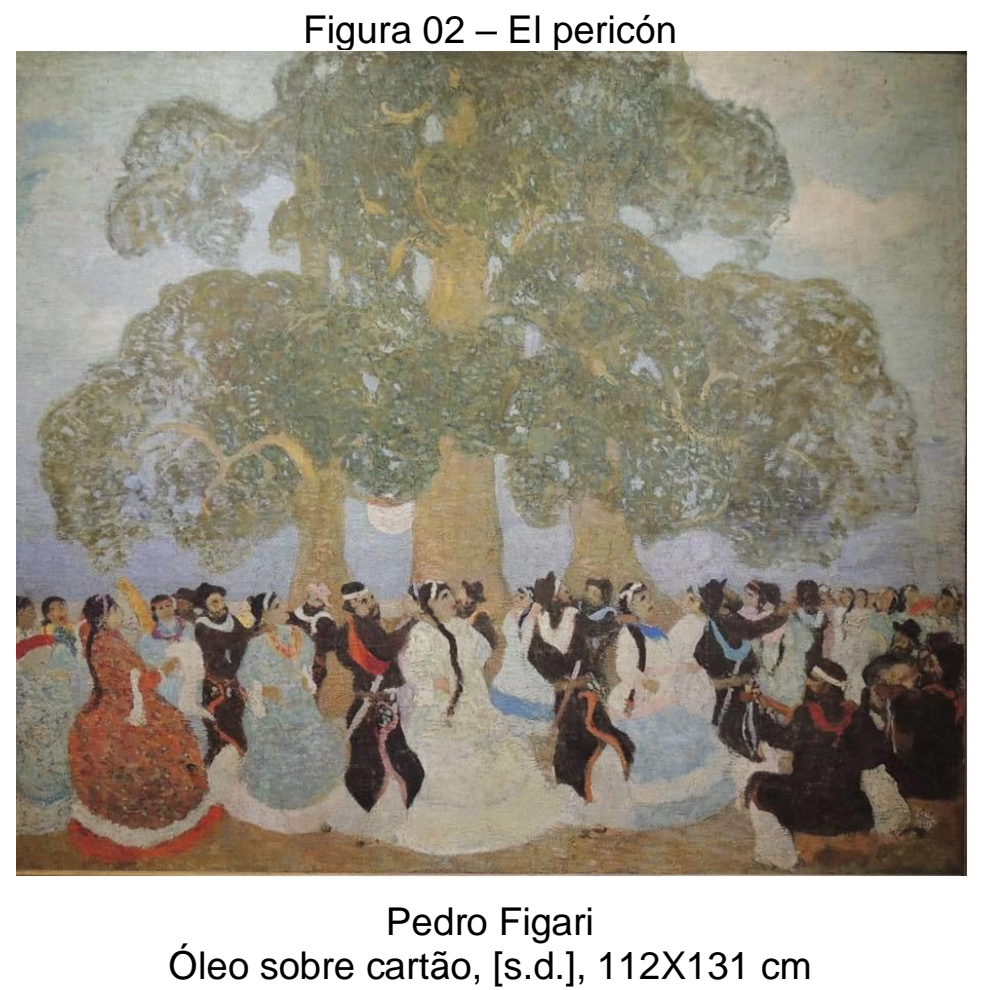

Museo Provincial de Bellas Artes Juan Manuel Blanes - Montevideo

A série alusiva aos gauchos desempenhando suas mais simples e cotidianas atividades está, portanto, no centro dessa questão. Ao elaborá-las, Figari não só apresentava o homem do campo como memória, mas, igualmente, como presente e como construção do futuro. Assim, observar os entremeios dessas produções pictóricas, onde muitas vezes os círculos intelectuais se tornam basilares para a análise, oportuniza a visualização de um gaucho imbuído de muitas outras significações.

O terceiro ponto que se objetiva comentar está relacionado ao fato de, muitas vezes e ainda hoje, se perceber a pintura como cópia da realidade objetiva. Sobre essa questão, muito se foi debatido na própria historiografia da arte, onde os elementos 
formais estavam muito mais próximos de atribuir valor às pinturas do que os demais elementos que as compunham. Nesse caso, escapa ao pesquisador, justamente, a possibilidade de perceber os entornos da obra uma vez que se fica preso aos aspectos estritamente compositivos da mesma.

Para incitar o debate, a pintura Rodeio, de Pedro Weingärtner (1853-1929), parece ser bastante elucidativa. A obra, encomendada pelo governador Carlos Barbosa ao, então, mais destacado pintor do Rio Grande do Sul, tinha um objetivo bastante claro: ela deveria mostrar uma cena típica e bastante característica do Estado. A notícia da encomenda, bem como a do andamento da pintura, circulou intensamente na imprensa republicana, como pode ser percebida na nota veiculada pelo jornal $A$ Federação:

(...) uma excellente [sic] reprodução photographica [sic], em miniatura, do bellissimo quadro - $\mathrm{O}$ rodeio (...). A palheta mágica do illustre pintor patrício illumina o quadro com aquele colorido e expressão própria do local, no estudo minucioso dos mínimos detalhes, que é o que dá destaque aos trabalhos de Weingärtner (NOTAS, 1908, p. 02).

Entre elogios e comentários suntuosos acerca da obra e de seu criador, aos poucos a população entrava em contato, também, com o que viria a ser a pintura.Se criava, assim, um imaginário - e uma expectativa - acerca da mesma.

Em 1909, um ano após a encomenda, Pedro Weingärtner, que à época residia em Roma, enviou para Porto Alegre, aos cuidados de seu irmão Miguel, a pintura finalizada. Antes de ser entregue, porém, ao poder público, a mesma foi exposta em uma vitrine na Rua dos Andradas. Foi neste momento, então, que o público, pela primeira vez, entrou em contato com a obra. E, ao contrário do que se esperava, ela foi criticada veementemente (GUIDO, 1956, p. 113). Dentre as críticas mais ferrenhas, estava o fato de que, possivelmente, Weingärtner teria cometido graves erros na representação dos costumes dos gaúchos. Tal situação fez com que o governo, apesar de ter encomendado a pintura, não mais a adquirisse.

Assim, em A Federação de 15 de maio de 1909, em texto crítico assinado pelo jornalista Arthur Toscano, era oficialmente divulgado que o governo não mais faria a aquisição da pintura. Segundo o texto, e após elencar todas as qualidades técnicas e consagratórias de Weingärtner, coloca Toscano: "Sentimos, extraordinariamente, ter de dizer que, apesar de todos esses requisitos e aprestos, o quadro do sr. Pedro Weingärtner está consideravelmente distanciado das joias artísticas que o seu pincel até agora tem produzido" (TOSCANO, 1909, p. 01). 


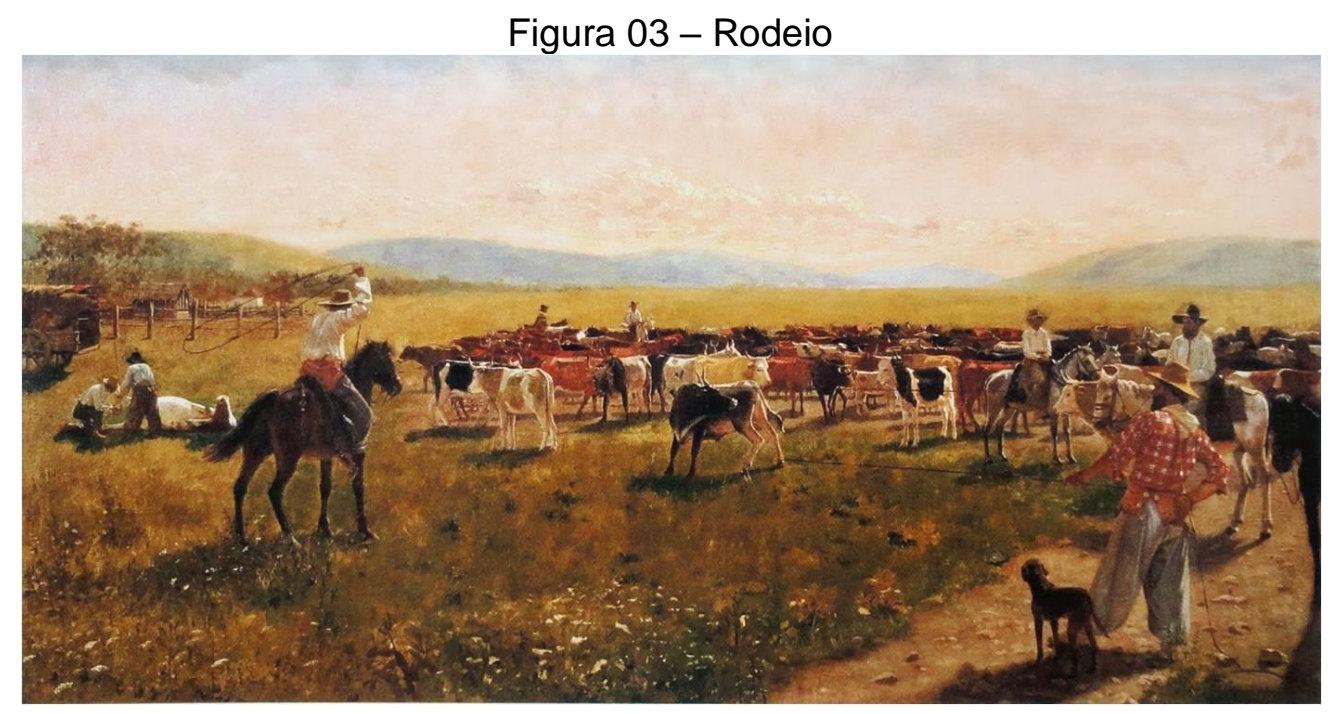

Pedro Weingärtner

Óleo sobre tela, $1908,50 \times 100 \mathrm{~cm}$

Coleção Carlos F. de Carvalho - Rio de Janeiro

Ao tecer tal comentário, o jornalista passa a justificar, a partir de dois grandes eixos, o motivo pela qual a obra não se adequou aos auspícios governamentais. $O$ primeiro deles estava relacionado a tradição, ou seja, "(...) a scena [sic] pintada pelo Sr. Weingärtner não representa um rodeio, tal como esse quadro da vida campeira do Rio Grande do Sul é conhecida e se passa (...)" (TOSCANO, 1909, p. 01). A outra questão centrava-se, pois, na execução plástica da pintura, onde o jornalista apontava graves falhas compositivas. Ao final do artigo, ele resume:

O sr. Pedro Weingärtner não foi feliz pintando um quadro de costumes peculiares, complexos, que se não traduzem como uma enscenação [sic] ad hoc nem com o auxílio de vistas photográphicas. Seria preciso ao artista viver aqui, sentir o seu assumpto, identificar-se com a tradição e observar minuciosamente os elementos com que poderia traduzil-o [sic] com fidelidade ao menos relativa (TOSCANO, 1908, p. 01).

Sem entrar nos pormenores dos erros apontados na obra, importa sublinhar a relevância desse acontecimento não apenas para o panorama artístico porto-alegrense, mas, sobretudo, para a forma como a pintura - e mais particularmente a imagem - e suas significações eram entendidas pela sociedade do período. A partir do momento em que Rodeio é posta à mostra, e torna-se visível aos olhos dos apreciadores e observadores que até então haviam imaginado a pintura através das notas do jornal - um misto de 
reprovação e frustração parece acometê-los. E isso se deveu, fundamentalmente, ao fato de, ao observarem a cena pintada, não reconhecerem sua veracidade factual. Isto é, o entendimento acerca da obra, bem como sua apreciação, estavam fortemente vinculados aos referenciais representacionais da realidade.

Nesse sentido, Rodeio não pode ser analisado apenas pelo seu viés compositivo e formal, uma vez que tanto seu entorno de produção quanto sua recepção e circulação, oferecem importantes indícios para se perceber detalhes importantes acerca de parcela da sociedade porto-alegrense do início do século, bem como sua relação com as produções pictóricas. Em última instância, são silêncios obliterados pela investigação mais aprofundada da pintura que, igualmente, contribui para a tessitura de outros fios e teias da ampla e complexa rede de relações em que as imagens estão inseridas.

Para finalizar, a quarta e última questão que envolve silêncios e imagens está voltada ao mural $A$ formação histórico-etnográfica do povo rio-grandense, de Aldo Locatelli.Como o próprio título já evidencia, o mural tinha por fundamento apresentar os elementos étnicos e históricos na formação do gaúcho e do Rio Grande do Sul. Encomendando pelo então governador Ernesto Dornelles no ano de 1951, essa pintura fez parte de um grande projeto artístico ${ }^{3}$ levado a cabo em seu governo. Ao serem retiradas as pinturas de história que, desde as primeiras décadas do século $X X$, adornavam as salas do prédio governamental, Dornelles visava não só trazer elementos históricos do Estado, mas, sobretudo, alguns marcos de seu desenvolvimento.

Há, nesse mural, uma significativa profusão de imagens que dialogam entre si. O artista, ao elaborá-lo a partir de uma narrativa circular, apresenta, então, a base histórica e étnica do Rio Grande do Sul.As figuras que o compõem são, em linhas gerais, elementos de fácil reconhecimento pelo observador, uma vez que, apreendendo os elementos formativos da história sulina, quase todos são facilmente identificados. No primeiro plano da pintura está, além do gaúcho e sua família, um casal de agricultores e, também, algumas cabeças de gado, aludindo à pecuária; no segundo plano - e elaborados em tonalidades mais claras - está um soldado português, um grupo de bandeirantes e, centralizado, um índio missioneiro. Ao centro do mural, como que

\footnotetext{
${ }^{3}$ Dentre as pinturas encomendadas pelo governador, estavam, também, A fundação de Rio Grande, $O$ Estado e os dezoito murais alusivos à lenda do Negrinho do Pastoreio. Para maiores detalhamentos, ver: OLIVEIRA, Luciana da Costa de. O Rio Grande do Sul de Aldo Locatelli. Arte, historiografia e memória nos murais do Palácio Piratini. Porto Alegre, 2011. Dissertação (Mestrado em História) - Faculdade de Filosofia e Ciências Humanas, Pontifícia Universidade Católica do Rio Grande do Sul.
} 
finalizando a narrativa, está o gaúcho e seu cavalo saltando sobre o mapa do Rio Grande do Sul.

Figura 04 - A formação histórico-etnográfica do povo rio-grandense

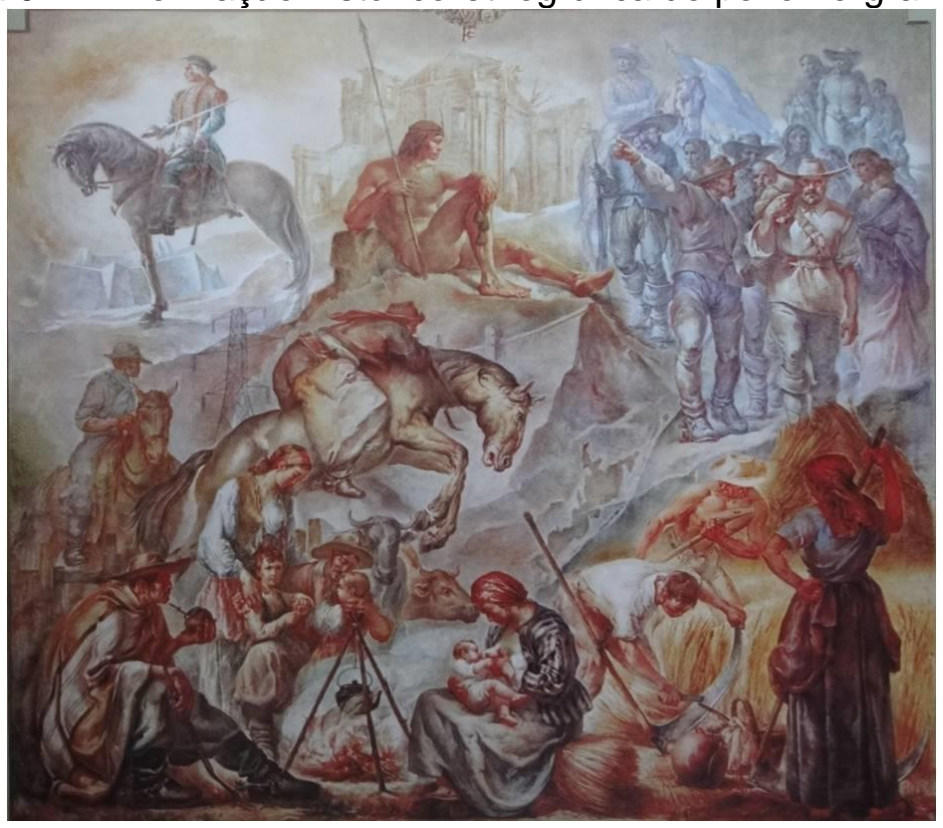

Aldo Locatelli

Mural em técnica mista - 1951/55 - $25 \mathrm{~m}^{2}$

Palácio Piratini - Porto Alegre

Por certo, o observador que se posta à frente desse grande mural, faz percorrer seu olhar por todos os personagens que, de certa forma, formaram histórica e etnicamente o Estado do Rio Grande do Sul. No entanto, observá-lo mais acuradamente, dando atenção aos detalhes do mesmo, especialmente àqueles que não foram elaborados a partir de cores destacadas, proporcionam a visualização de dois elementos que, ao mesmo tempo em que estão distantes temporalmente das demais imagens do mural, igualmente dialogam com as propostas de desenvolvimento do Estado. Nesse caso, tanto a torre de energia quanto a barragem hidrelétrica que aparecem no último plano da pintura pareceriam estranhas ao observador se as questões que envolveram sua encomenda não fossem problematizadas. 
Figura 05 e 06 - A formação histórico-etnográfica do povo rio-grandense - detalhes
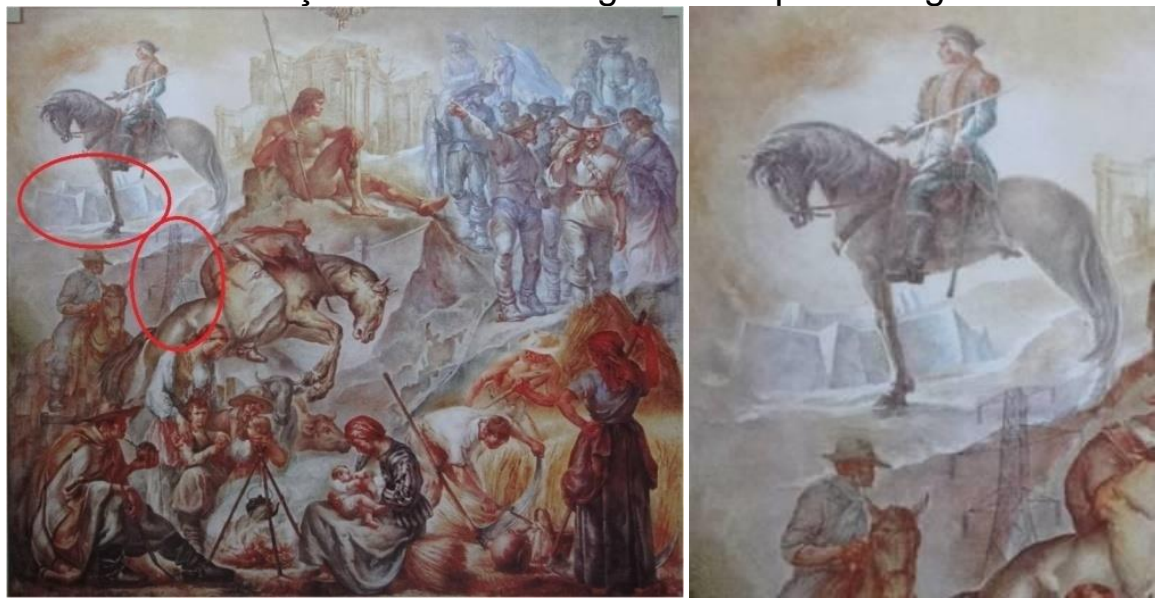

Aldo Locatelli

Mural em técnica mista - 1951/55 - $25 \mathrm{~m}^{2}$

Palácio Piratini - Porto Alegre

A percepção dessas duas pequenas imagens, que de certa maneira agitam o olhar e perturbam o observador mais atento, faz com que se levantem inúmeros questionamentos, sendo o principal deles a função que ambas exercem no conjunto da obra. Um possível caminho para responder tal indagação reside, pois, na relação do comitente com o artista. Sem dúvidas, ao encomendar o monumental mural a Aldo Locatelli, Ernesto Dornelles referenciava - e reverenciava - a história e o passado, mas, igualmente, sugeria, através do pedido da inserção da torre e da barragem hidrelétrica, as marcas e feitos do presente. Seu governo, por exemplo, foi o responsável por grande parte da eletrificação do Estado. Assim, seu pedido a Locatelli, por mais dissonante que seja dentro da narrativa construída e idealizada pelo artista, era uma forma de perenizar seus feitos no tempo. Por conseguinte, observar esse mural é, como afirma o historiador e filósofo da arte Georges Didi-Huberman, deparar-se diante de uma profusão de tempos e memórias.

A modernidade diante do passado. Ou, mesmo, o passado defronte à modernidade. Assim pode ser percebido, também, esse mural. Quando detalhes perturbam o olhar, sem dúvidas, promovem novas inquietações. E são justamente elas que permitem um mergulho nos elementos que, apesar de escondidos e silenciosos, dãose a ver, de alguma forma, ao observador e ao pesquisador. 
Pensemos em uma grande teia. Todos os fios que a constituem, sem dúvidas, são de fundamental importância para sua existência. Assim ocorre, também, com as imagens. Ocupando o centro da teia, são os mais diversos elementos que estão em seu entorno, seja ele compositivo ou o que envolve o artista, que oportunizam a tessitura de novas problematizações e, por conseguinte, de novos conhecimentos.

Ao focar o estudo em quatro questões, pensou-se em iniciar a quebra do silêncio pela qual as fontes visuais, por muito tempo, foram submetidas. Por serem, muitas vezes, objetos utilizados apenas com fins ilustrativos, suas particularidades e, mais precisamente, suas potencialidades para a construção do conhecimento histórico não eram consideradas. Assim, questionar a imagem a partir dos seus silêncios é, também, permitir-se adentrar em um labirinto onde os mais diferentes caminhos, em algum momento, se unem e oferecem uma nova porta de entrada - ou de saída.

Assim, mesmo que trabalhadas muito brevemente, as questões levantadas acerca de cada obra e artista atentam para a importância dos silêncios. Atentam para a forma como esse mutismo - ou invisibilidade - descortina, para o pesquisar, uma ampla gama de possibilidades. Tomando novamente as palavras de Jayme Caetano Braun, seriam, por fim, as imagens e seus silêncios as luzes que despertam para o novo e para a tessitura de novos saberes.

\section{Referências}

BING, Gertrud. Prefácio à edição de 1932. In: WARBURG, Aby. A renovação da Antiguidade pagã: contribuições científico-culturais para a história do Renascimento europeu.Rio de Janeiro: Contraponto, 2013.

DIDI-HUBERMAN, Georges. Ante eltiempo. Historia del arte y anacronismo de lasimágenes. Buenos Aires: Adriana Hidalgo, 2008.

DIDI-HUBERMAN, Georges. A imagem sobrevivente. História da arte e tempo dos fantasmas segundo AbyWarburg. Rio de Janeiro: Contraponto, 2013.

FIGARI, 1924. Autonomia regional. La cruz delsur, Montevideo, ano I, n. 2, mai. 1924, [s.p.]. 
FOGLIA, Carlos. Cesáreo Bernaldo de Quirós. Buenos Aires: Ediciones Culturales Argentinas, 1961.

GUIDO, Ângelo. Pedro Weingärtner. Porto Alegre: Divisão de Cultura, 1956.

NOTAS. A Federação, Porto Alegre, 03 dez., 1908, p.02.

OLIVEIRA, Luciana da Costa de. O Rio Grande do Sul de Aldo Locatelli. Arte, historiografia e memória nos murais do Palácio Piratini. Porto Alegre, 2011. Dissertação (Mestrado em História) - Faculdade de Filosofia e Ciências Humanas, Pontifícia Universidade Católica do Rio Grande do Sul.

SAMAIN, Etiènne (Org.). Como pensam as imagens. Campinas: Unicamp, 2012.

TOSCANO, Arthur. Rodeio, quadro de Pedro Weingärtner. A Federação, Porto Alegre, 15 mai. 1909 , p.01.

WARBURG, Aby. Introdução à Mnemosine. In: WAINZBORT, Leopoldo (Org.). Histórias de fantasmas para gente grande: escritos, esboços e conferências/AbyWarburg. São Paulo: Companhia das Letras, 2015.

ZALDÍVAR, Ignácio Gutiérrez. Quirós. Buenos Aires: Zurbarán, 1992. 